\title{
Review: rapid cycling bipolar disorder associated with female gender and bipolar type II subgroup
}

Kupka RW, Luckenbaugh DA, Post RM, et al. Rapid and non-rapid cycling bipolar disorder: A metaanalysis of clinical studies. J Clin Psychiatry 2003;64:1483-94.

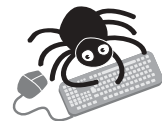

This article

contains extra text on the EBMH website

\section{What risk factors are associated with rapid versus non-rapid cycling in people with bipolar disorder?}

\section{METHODS}

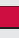

Design: Systematic review with meta-analysis.<smiles>[BH2-]</smiles>

口

Data sources: MEDLINE (1974-2002) plus hand search of 을

bibliographies and book chapters.

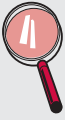

Study selection and analysis: Eligible studies compared people with rapid cycling ( $\geqslant 4$ mood episodes/year) and non-rapid cycling bipolar disorder; clearly described selection of participants, diagnostic criteria, stated whether rapid cycling was lifetime or current and assessed 18 potential risk factors (reported by at least three studies) associated with rapid cycling. Studies in that only selected people with rapid cycling were excluded. Mean random effect sizes for potential risk factors were calculated.

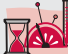

Outcomes: Prevalence of rapid cycling; association of potential risk factors with rapid cycling (effect size).

\section{MAIN RESULTS}

Twenty studies $(\mathrm{n}=3709)$ from five countries met inclusion criteria. Prevalence of rapid cycling: $16 \%$ of participants were diagnosed with rapid cycling (335 of 2054 participants from eight papers). Risk factors: most effect sizes were small. Female sex and bipolar II subtype were significantly associated with rapid cycling (see http:// www.ebmentalhealth.com/supplemental for table). Association with rapid cycling and failure of prophylactic lithium to prevent future episodes, depression at onset, family history of major affective disorder, and history of suicide attempt almost reached significance. Age, duration of illness, age at onset, family history or risk of bipolar disorder, family history or risk of major depression, family risk of any affective disorder, failure to achieve at least 50\% improvement with lithium prophylaxis or hypothyroidism were not significantly associated with rapid cycling.

\section{CONCLUSIONS}

Rapid cycling is slightly more prevalent in women and people with bipolar II subtype.

\section{NOTES}

Most studies had a naturalistic design and there was heterogeneity of methodology and outcome criteria, limiting comparability.

For correspondence: Ralph Kupka, Altrecht Institute for Mental Heath Care, Lange Nieuwstraat 119, 3512 PG Utrecht, the Netherlands; r.kupka@planet.nl

Sources of funding: the Stanley Medical Research Institute, Bethesda, MD USA.

\section{Commentary}

$\mathrm{R}$ apid cycling, and its sibling mixed states, is a clinically significant and understudied variant of bipolar disorder. There is nevertheless controversy regarding the definition of rapid cycling. ${ }^{1}$ The importance of rapid cycling reflects the differences in clinical features, course, and outcome, extensively covered in this review. It is a more severe variant, with greater morbidity and is often more treatment refractory. There is evidence that cycle length shortens with increasing number of episodes. ${ }^{2}$ Furthermore, the authors cover data suggesting antidepressants, especially if used without mood stabiliser cover, can shorten cycle length ${ }^{3}$ and induce rapid cycling. However the association of antidepressants with rapid cycling has been argued to reflect the depressive predominance in rapid cycling. ${ }^{4} 5$ Opinion has swung to reflect greater caution with regard to the role of antidepressants. Rapid cycling can therefore be seen at least in part as a consequence of misdiagnosis and mistreatment. This suggests that shortening the latency to appropriate therapy can reduce the incidence of rapid cycling. The authors furthermore present the limited available data on differential response to therapy in this subgroup, particularly the lower rates of lithium response. Combination mood stabiliser strategies are widely used in practice, despite the absence of controlled efficacy data. Placebo controlled long term data is however currently restricted to lamotrigine. ${ }^{6}$ There is a clear need for further prospective data on other potential agents such as the atypical agents ${ }^{7} 8$ and combination strategies in this indication. This paper emphasises the importance of the recognition of rapid cycling, and highlights many significant clinical, prognostic, and therapeutic differentiators.

Michael Berk, MBBCh, MMed(Psych), FF(Psych)SA, FRANZCP, PhD Professor of Psychiatry, Barwon Health and Geelong Clinic, University of Melbourne, Australia Seetal Dodd, PhD University of Melbourne, Australia

1 Maj M, Pirozzi R, Formicola AMR, et al. Reliability and validity of four alternative definitions of rapid cycling bipolar disorder. Am J Psychiatry 1999;156:1421-4.

2 Roy Byrne P, Post RM, Uhde TW, et al. The longitudinal course of recurrent affective illness: life chart data from research patients at the NIMH. Acta Psychiatr Scand 1985;317(suppl): 1-34.

3 Wehr TA, Goodwin FK. Can antidepressants cause mania and worsen the course of affective illness? Am J Psychiatry 1987;144:1403-11.

4 Calabrese JR, Shelton M, Bowden CL, et al. Bipolar rapid cycling; Focus on depression as its hallmark. J Clin Psychiatry 2001;62(Suppl 14):34-41.

5 Coryell W, Endicott J, Keller M, et al. Rapid cycling affective disorder: Demographics, diagnosis family history and course. Arch Gen Psychiatry 1992:49:126-31.

6 Calabrese JR, Suppes T, Bowden CL, et al. A double blind placebo controlled prophylaxis study of lamotrigine in rapid cycling bipolar disorder. J Clin Psychiatry 2000;61:841-50.

7 Vieta E, Parramon G, Padrell E, et al. Quetiapine in the treatment of rapid cycling bipolar disorder. Bipolar Disord 2002;4:335-40.

8 Sanger TM, Tohen $M$, Vieta E, et al. Olanzapine in the acute treatment of bipolar I disorder with a history of rapid cycling. I Affect Disord 2003;73:155-61. 